\title{
Analysis of FDS 6 simulation results for planar air curtain related flows from straight rectangular ducts
}

\author{
Long-Xing $\mathrm{Yu}^{1,2}$, Tarek Beji ${ }^{2}$, Fang Liu ${ }^{1}$, Miao-Cheng Weng ${ }^{1}$, Bart Merci ${ }^{2}$ \\ ${ }^{I}$ Chongqing University, Faculty of Urban Construction and Environmental Engineering, Chongqing, China \\ ${ }^{2}$ Ghent University - UGent, Dept. of Flow, Heat and Combustion Mechanics, Ghent, Belgium
}

\begin{abstract}
CFD results are discussed for jet flows through a straight square duct, which is an interesting configuration in the context of air curtain flows for smoke and heat control in buildings in case of fire. The CFD package FDS (Fire Dynamics Simulator), Version 6.0.1, is used. Special focus is given to the impact of the inlet boundary condition on the flow field in the near-field region. Investigation of different orifice configurations ( $W=2 \mathrm{~cm}$ width, variable span-wise length), including calculations inside a straight square duct $(2 \mathrm{~cm} \times 2 \mathrm{~cm}$, with variable length) ahead of the air orifice, reveals a small vena contracta effect when the orifice is flush with a solid boundary, leading to an acceleration of the flow in the symmetry plane in the near-field region. The vena contracta effect disappears if the co-flow at the nozzle exit is aligned with the jet. More important is the effect of the duct length (precursor domain length, serving as method to generate inflow turbulent conditions for the main computation): imposing a top hat velocity profile, a sufficiently long duct (i.e., $L=20 \mathrm{~W}$ ) is required for the flow to become fully developed at the orifice. The CFD results confirm an analytical correlation for the ratio of the entrance length to the hydraulic diameter of the duct as function of the Reynolds number, provided the duct width is used as characteristic length scale. Using a sufficiently fine mesh, i.e., 10 cells across the characteristic dimension of the nozzle, the evolution of the mean and RMS stream-wise velocity along the centerline, as well as their profiles across the nozzle width, are shown to be captured accurately in the CFD results.
\end{abstract}

Key words: Air curtain; Duct flow; Boundary condition; CFD; FDS. 


\section{Introduction}

Smoke has been reported to be the most fatal factor in fires [1]. In order to prevent the smoke from causing a harmful environment for the building occupants, a smoke and heat control system can be applied to control and remove heat and smoke induced by fire [2]. For instance, the pressurization of stairwells is a commonly used smoke control system in buildings. However, large air supply volumes are required. Therefore, an air curtain could be a more efficient way of blocking smoke dispersion during fires [3].

Air curtains can be considered as compartmentation devices, based on the discharge of a plane jet. Therefore, it is interesting to study plane jets, particularly in the so-called 'near-field region', i.e., the region close to the air orifice, as often air curtains mainly block smoke in regions close to the nozzle exits. It is worth noting that plane jets have also found their practical application in a variety of industrial applications. Some of the major applications occur in reducing dispersed pollution in urban road tunnels [4], in controlling pollutant spreading for emergency management in cleanrooms [5], in preserving low temperatures for refrigerated storage rooms or cabinets [6], or in preventing moisture in semiconductor manufacturing processes [7].

In the context of fire, air curtains can be used to prevent smoke spreading from one volume to an adjacent volume. According to Chinese Machinery Industry Standard: Air Curtain (JB/T $9067-1999)$, the nominal air velocity at the nozzle outlet is $4-9 \mathrm{~m} / \mathrm{s}$ for commercial and civil buildings, and $8-24 \mathrm{~m} / \mathrm{s}$ for industrial buildings [8]. In recent years, more and more studies on air curtains have appeared in the literature, labeling it as an effective way to confine smoke (e.g., [9-12]).

A few publications, using Fire Dynamics Simulator (FDS) as CFD package further illustrate that air curtains are useful for smoke confinement during an accidental fire [13-17]. The present 
paper focuses on the near-field regions, with the following novel aspects: 1) A recent version (6.0.1) of FDS [18] is used. Compared to the previous versions, the turbulence modeling has been updated substantially (along with, e.g., combustion modeling and radiation modeling, but this is less relevant for the study at hand). 2) The simulation of a duct flow, serving as 'prior' simulation to obtain the inlet boundary condition for the turbulent flow from the nozzle exit into the domain is discussed. This method is similar to what was reported in [19]. 3) The main focus is on the impact of the velocity inlet boundary condition on the flow in the near-field region. 4) The mesh sensitivity of the results is analysed.

\section{Physics of the free jet}

The theoretical solution of the plane turbulent free jet is a statistically two-dimensional flow [20-23] with dominant mean motion in the stream-wise (X) direction, jet spreading in the lateral (Y) direction and zero entrainment in the span-wise $(\mathrm{Z})$ direction. Briefly, a free jet can be divided into three regions [24]: an 'initial' or 'core' region, a 'transition' or 'interaction' region and a 'developed' or 'self-similarity' or 'far-field' region (Fig. 1).

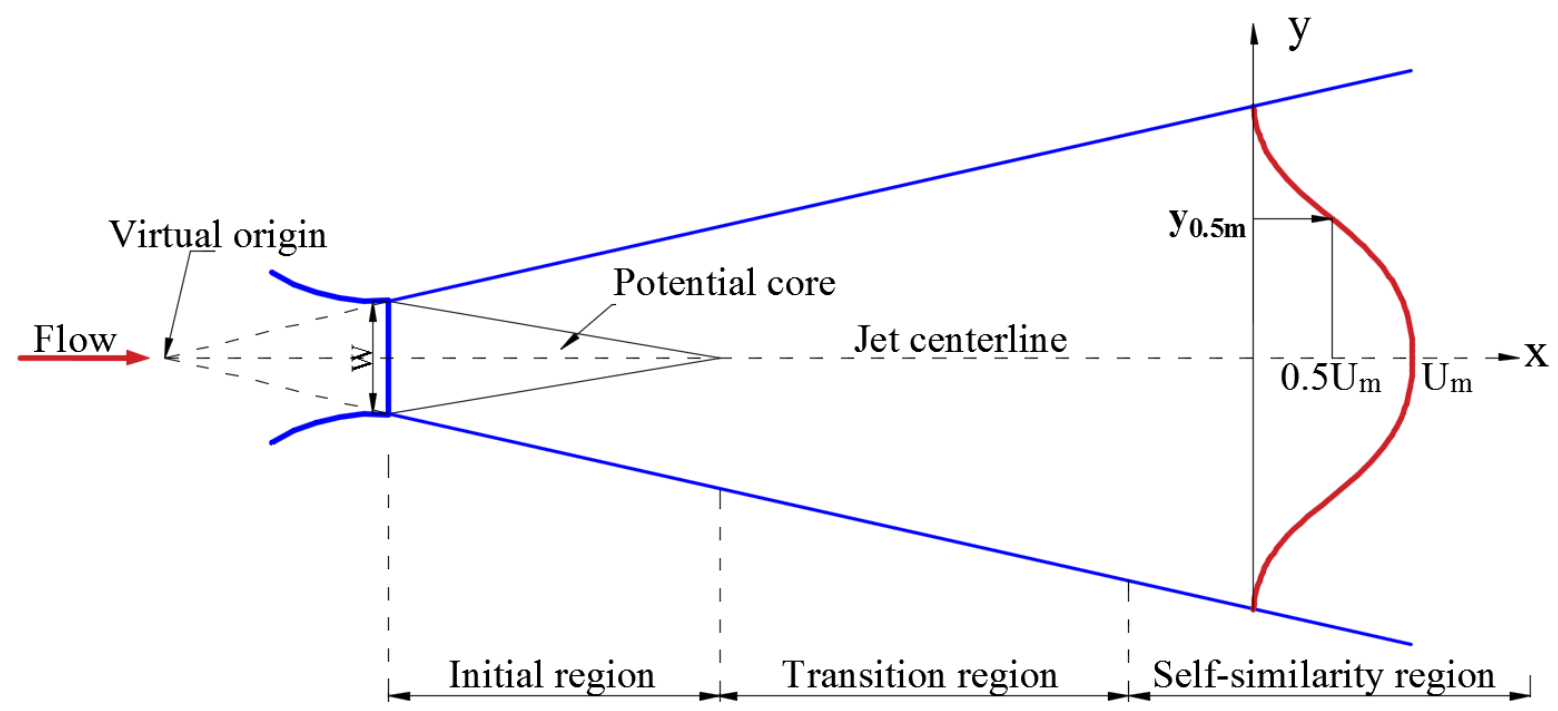

Fig. 1. A schematic view of the time-averaged flow field of a plane jet. Redrawn after Browne et al. (1984) [24]. 
In the core region, the centerline velocity remains constant, equal to the jet velocity at the nozzle exit. The turbulence intensity is constant as well. The length of potential core equals 4 to 6 times the jet thickness $\mathrm{W}$. The transition region behind the core region extends from $6 \mathrm{~W}$ to $20 \mathrm{~W}$. In this region the velocity starts to decay. Further downstream the flow reaches the self-similarity region, where normalized transverse profiles of (normalized) velocity are similar, independent of the distance $\mathrm{X}$ from the nozzle exit. The present study focuses on the near-field region, i.e., the 'initial' or 'core' region.

\section{General set-up of the simulations}

Large Eddy Simulations (LES) as implemented in the Fire Dynamics Simulator (FDS), Version 6.0.1 [25], are used to account for turbulence in the CFD simulations. The default sub-grid scale (SGS) model, namely the modified Deardorff turbulence model [26], is applied, with the default model constant $C_{v}=0.1$.

The free jet flow downstream is strongly influenced by the orifice configuration and inlet boundary condition [27]. Thus, different computational domains have been used, depending on the orifice configuration and dimension, labeled A-C (Fig. 2). For orifice configuration A, the velocity inlet is set flush with the bottom of the domain (floor), while for configuration B and $\mathrm{C}$ a duct is added, so that the velocity inlet boundary condition is imposed upstream of the actual orifice. In configuration $\mathrm{C}$, the entrance duct has been moved inside the flow domain such that entrainment is primarily an axial co-flow, rather than radially inward flow. 


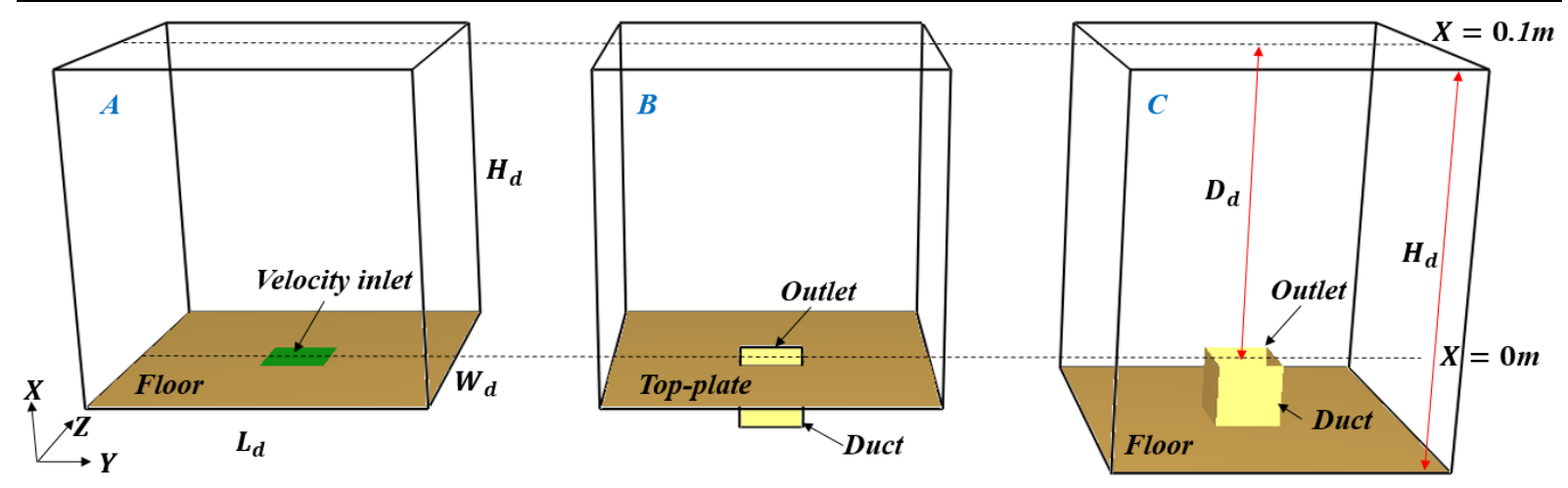

Fig. 2. Sketch of orifice configuration $A-C$.

Table 1 provides an overview with details for the computational domains. Cubic cells are used in all simulations. For domain I, the domain width $\left(W_{d}\right)$, length $\left(L_{d}\right)$ and Height $\left(H_{d}\right)$ are set to $10 \mathrm{~cm}$, which is 5 times the orifice width $(W=2 \mathrm{~cm})$. These results are included to investigate the near-field jet flow region at relatively low computational cost. The number of cells across the orifice width varies from 1 to 10 , i.e., the cell size varies from $2 \mathrm{~cm}$ to $0.2 \mathrm{~cm}$.

Table 1. Overview of characteristics of computational domains.

\begin{tabular}{|c|c|c|c|c|}
\hline $\begin{array}{l}\text { Domain } \\
\text { number }\end{array}$ & $\begin{array}{c}\text { Orifice } \\
\text { configuration }\end{array}$ & $\begin{array}{c}\text { Orifice } \\
\text { dimension } \\
\text { (cm) }\end{array}$ & $\begin{array}{l}\text { Number of cells } \\
\text { across the orifice } \\
\text { width }\end{array}$ & $\begin{array}{l}\text { Duct length } \\
\text { (cm) }\end{array}$ \\
\hline I & A & $\begin{array}{l}\text { Square } \\
(2 \times 2)\end{array}$ & $1,2,3,4,5,8,10$ & 0 \\
\hline II & B & $\begin{array}{l}\text { Square } \\
(2 \times 2)\end{array}$ & 10 & $2-80$ \\
\hline III & $\mathrm{C}$ & $\begin{array}{l}\text { Square } \\
(2 \times 2)\end{array}$ & 10 & $2-80$ \\
\hline IV & B & $\begin{array}{l}\text { Rectangular } \\
(2 \times 40)\end{array}$ & 10 & 160 \\
\hline
\end{tabular}


For domains II and III, the domain width, length and distance from the velocity inlet to the top of domain $\left(D_{d}\right)$ are equal to $10 \mathrm{~cm}$, while the Height $\left(H_{d}\right)$ of the domain varies according to the length of the duct.

For domain IV, the orifice configuration B with duct length of $160 \mathrm{~cm}$ is applied. A rectangular orifice with dimension $2 \mathrm{~cm} \times 40 \mathrm{~cm}$ is adopted. Thus, the domain width $\left(W_{d}\right)$ and distance from the velocity inlet to the top of domain $\left(D_{d}\right)$ are kept equal to $10 \mathrm{~cm}$, while the length $\left(L_{d}\right)$ and Height $\left(H_{d}\right)$ of the domain are equal to $40 \mathrm{~cm}$ and $170 \mathrm{~cm}$ respectively.

The top and four side boundaries of the domain are open to the outside by specifying them to be 'OPEN'. The floor (marked in brown) is a 'solid' boundary condition. The orifice ('VENT'), marked in green, lies in the middle of the floor and has a velocity inlet boundary condition.

\section{Results and Discussion}

\subsection{Implementation and visualization of the inlet velocity boundary condition}

Implementation details concerning the velocity inlet boundary conditions in FDS, version 6.0.1, are found in the FDS manuals [26]. Yet, some brief discussion is devoted to this topic, because post-processing (visualization) does not fully reflect the implementation, due to interpolation of velocity values, stored in a staggered manner, to values on the corners of mesh cells. If the mesh is too coarse, this can be misleading, as reported in [16], a few features of which are briefly mentioned here.

It is common practice to impose a single velocity value $\left(U_{\text {input }}\right)$ at the inlet. A top-hat profile is expected then for the mean velocity. However, impermeability conditions are enforced at walls. Consequently, the question arises how this affects the inlet velocity profile. In order to investigate this, a study is performed first with a square orifice (with dimension $2 \mathrm{~cm} \times 2 \mathrm{~cm}$ ) 
in computational domain I. The imposed velocity is $U_{\text {input }}=5 \mathrm{~m} / \mathrm{s}$.
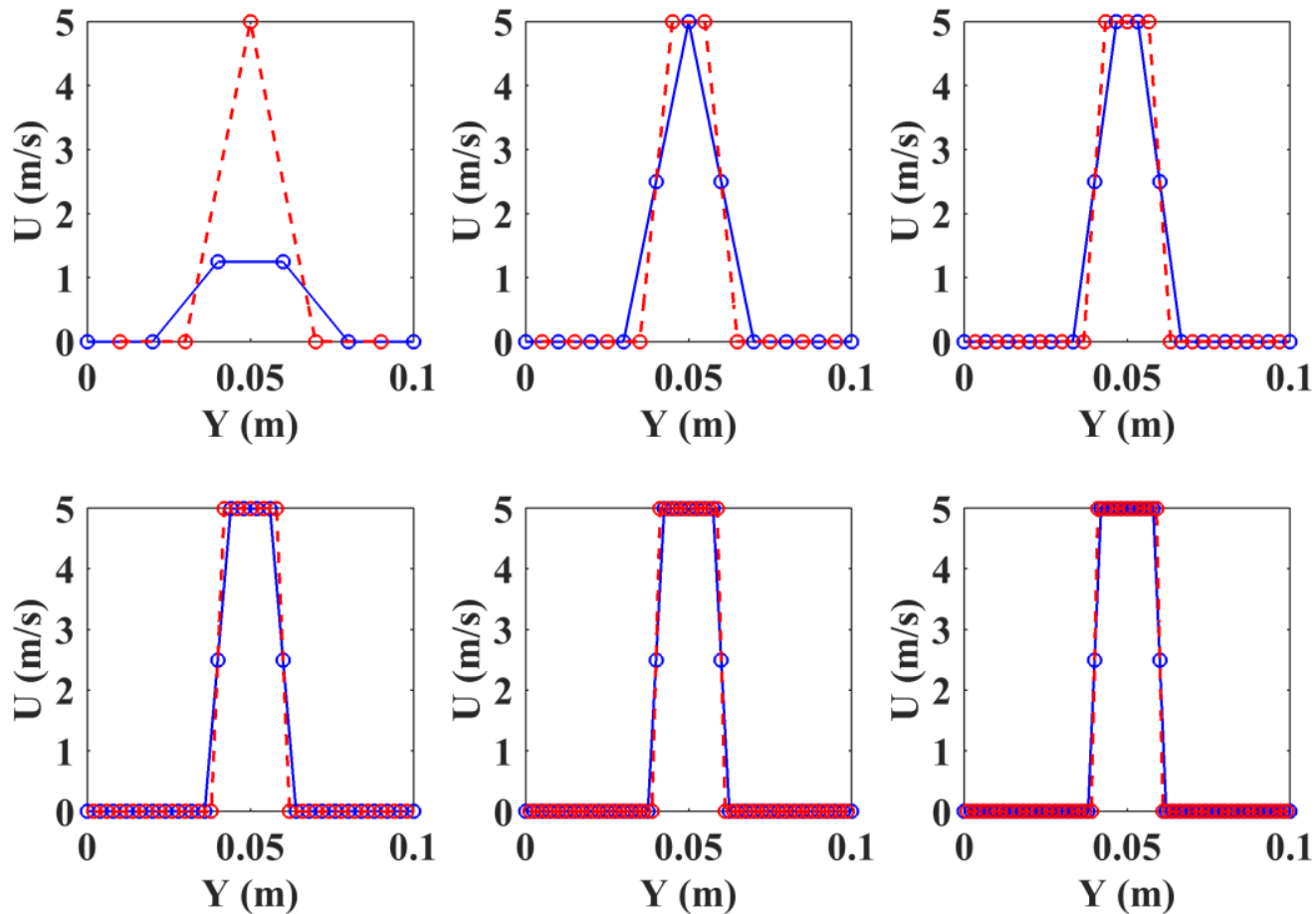

Fig. 3. Inlet velocity profile, retrieved as output in the inlet plane by using command of 'fds2ascii' (solid line) and 'DUMP'(dashed line). The square orifice has a width $w=2 \mathrm{~cm}$. The velocity, implemented in a staggered manner in FDS, is constant across the inlet $(5 \mathrm{~m} / \mathrm{s})$. Top row from left to right: 1, 2 and 3cell across the width, Bottom row from left to right: 5,8 and10 cells across the width.

Fig. 3 displays mean inlet velocity profiles, retrieved as output from the simulations, for different mesh cell sizes. An average over the period of the last 2 seconds of a total calculation time of 5 seconds is sufficient, as (quasi-)steady state conditions are reached after 2 seconds. A detailed discussion is devoted to this in section 4.3. Different methods are applied to obtain the velocity profiles. The solid line results have been collected from 'slice file' data by the command 'fds2ascii'. The data stored in the 'slice file' are visualized in Smokeview and most users rely upon this output directly. However, the data from the 'slice file' involve interpolation 
[16]. This can be prevented by outputting the raw (primitive) velocity data (dashed line) as actually computed by FDS by adding a 'DUMP' line with a 'UVW_TIMER' in the input file [26]. Fig. 3 reveals that differences become small for fine grids, but for coarser meshes the deviations are substantial, even at the level of mean velocity. In the extreme case with only one cell across the velocity inlet, one data point of $5 \mathrm{~m} / \mathrm{s}$ is imposed at the center of the cell face, but the linear interpolation in Smokeview yields an apparent maximum value of only $1.25 \mathrm{~m} / \mathrm{s}$ across the velocity inlet. Users should be aware of this artefact. Unless otherwise stated, all results in the following have been obtained avoiding the interpolation, i.e., using 'DUMP' line to obtain arrays of data or data matrix and 'DEVC' line for single data at specific locations.

It is important to acknowledge that 'DEVC' provides directly raw data from FDS (as long as 'TIME_AVERAGED = FALSE'). Similarly, in the most recent FDS versions there are wall variants of all such quantities to directly retrieve the boundary values. [Note that in the more recent FDS versions, combining the command 'CELL_CENTERED=.TRUE.' with 'VECTOR=.TRUE.' also shows the staggered velocity components.]

Fig. 4 presents the evolution of the mean velocity on the centerline in the potential core region. The impact of the mesh size is visible. The variation in inlet velocity (at $X=0$ ), as obtained from the output, has been explained above. However, the bottom figure of Fig. 4 rules out the differences at the inlet (by normalizing the velocity, using the mean exit velocity $\left(U_{0, c}\right)$ obtained at the center point of the orifice outlet). The velocity decays less rapidly as the mesh gets finer. Fig. 4 reveals a drop in velocity near the orifice in all curves. This is discussed next. 

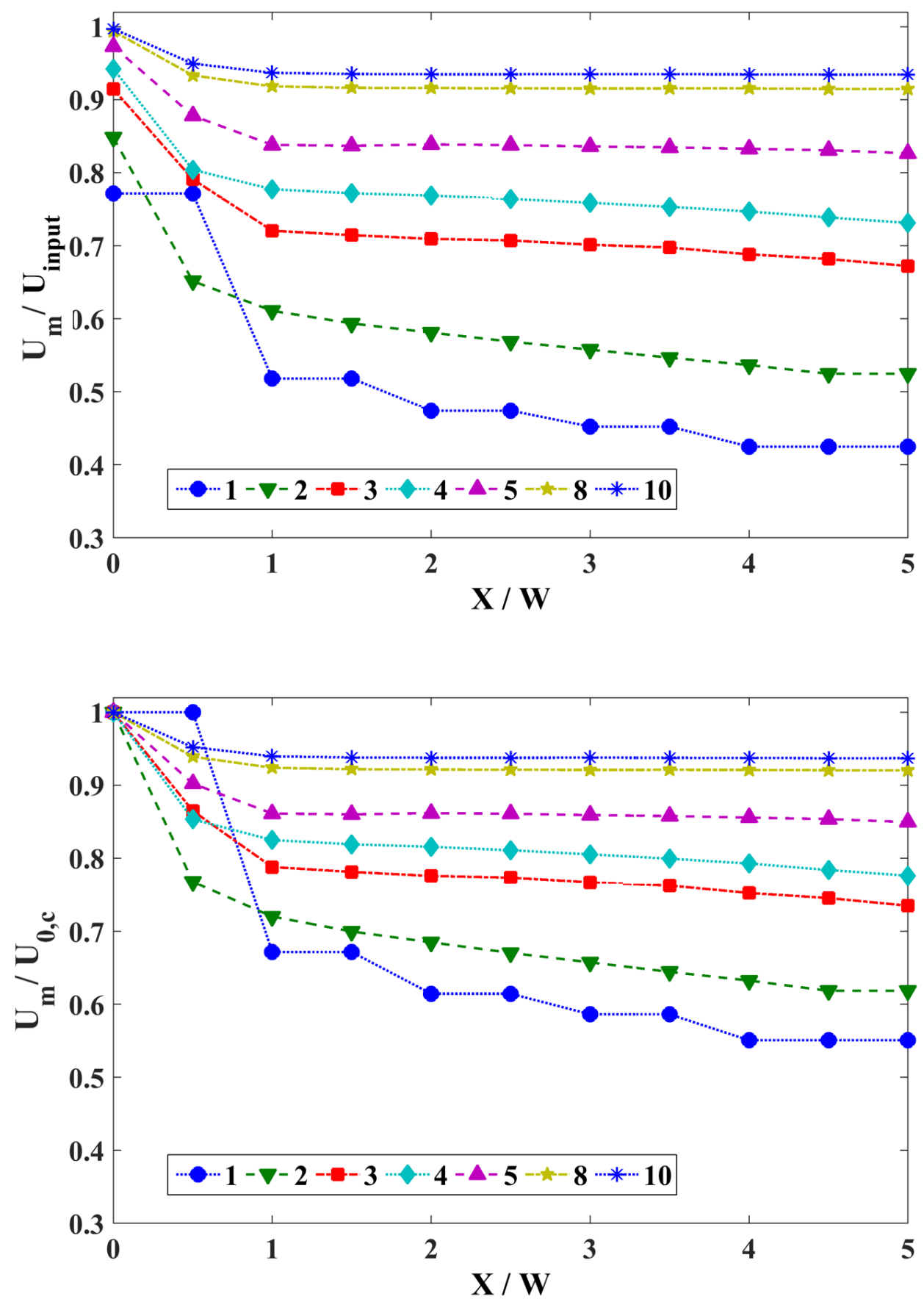

Fig. 4. Impact of the number of cells across the orifice width on the evolution of the centerline velocity with distance from orifice for configuration A. Top: output velocity, divided by imposed inlet velocity; bottom: output velocity, divided by the mean exit velocity $\left(U_{0, c}\right)$ obtained at the center point of the orifice outlet. Mark legend refers to the number of cells across the width of the orifice. 


\subsection{Orifice Configurations}

So far, the discussion has been restricted to the situation where the orifice is flush with the floor and the inlet velocity boundary condition is imposed in that plane ('configuration A', Fig. 2). In 'configuration B', a duct is added, so that the velocity inlet boundary condition is imposed upstream of the actual orifice. In this case, there is an evolution from the top-hat profile at the inlet of the domain to a profile that emerges from the orifice. Obviously, the length of the duct will affect the velocity profile, as long as the flow is not fully developed inside the duct. This is discussed below. 'Configuration C' (Fig. 2, right) has been added to this study in order to examine the vena contracta effect at the orifice exit.

Fig. 5 illustrates the impact of the duct length and the configuration on the velocity profile, emerging from the orifice. 10 cells have been applied across the orifice width. For configurations $\mathrm{B}$ and $\mathrm{C}$, many different duct lengths have been simulated. A duct length of approximately 15 to 20 hydraulic diameters is required to obtain a fully developed flow inside the duct, starting from the top hat profile (see below, section 4.3). Fig. 5 shows results for only 2 duct lengths, namely $5 \mathrm{~W}$ and $35 \mathrm{~W}$. In the latter, the flow is fully developed, whereas in the former the flow is still accelerating in the middle of the duct as it emerges from the orifice. 


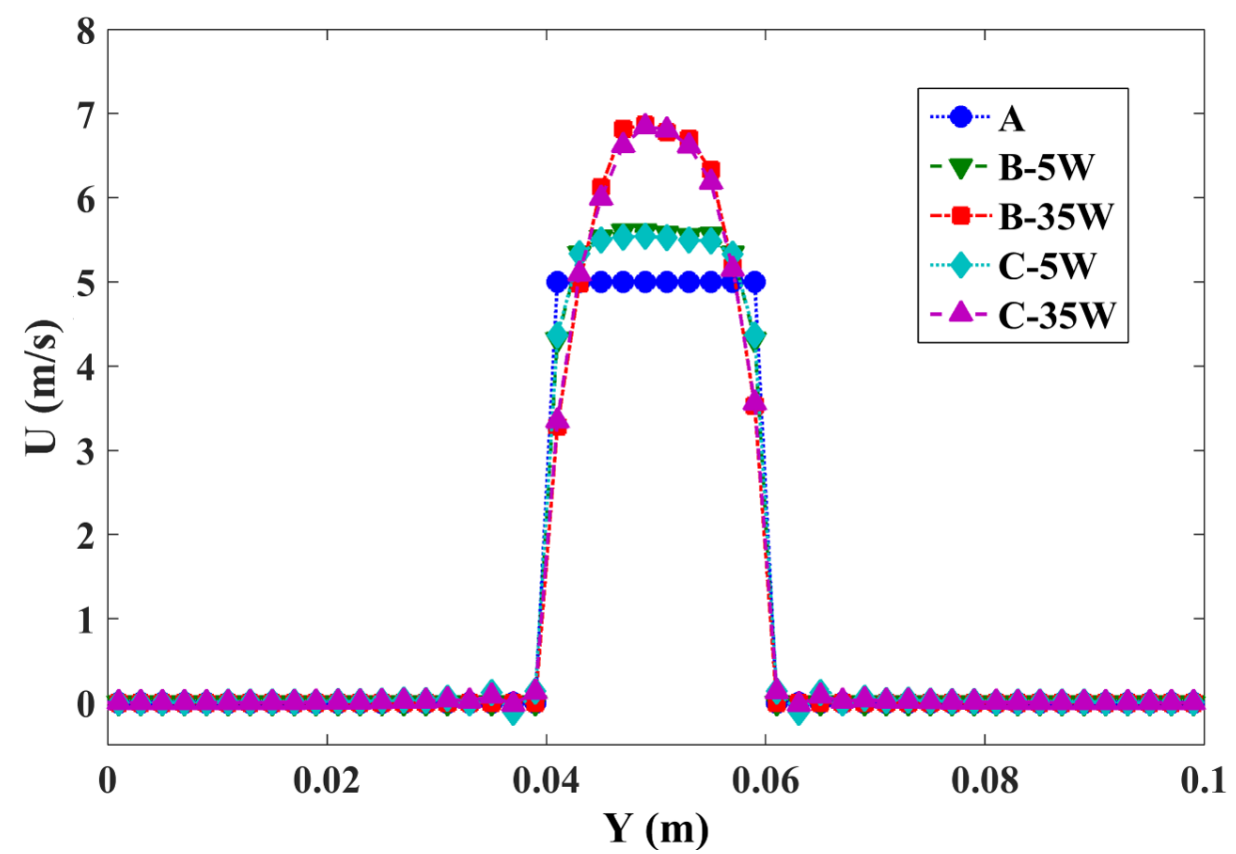

Fig. 5. Impact of configuration and duct length on the inlet velocity profile, raw value computed in the inlet plane. The square orifice has a width $W=2 \mathrm{~cm}$.

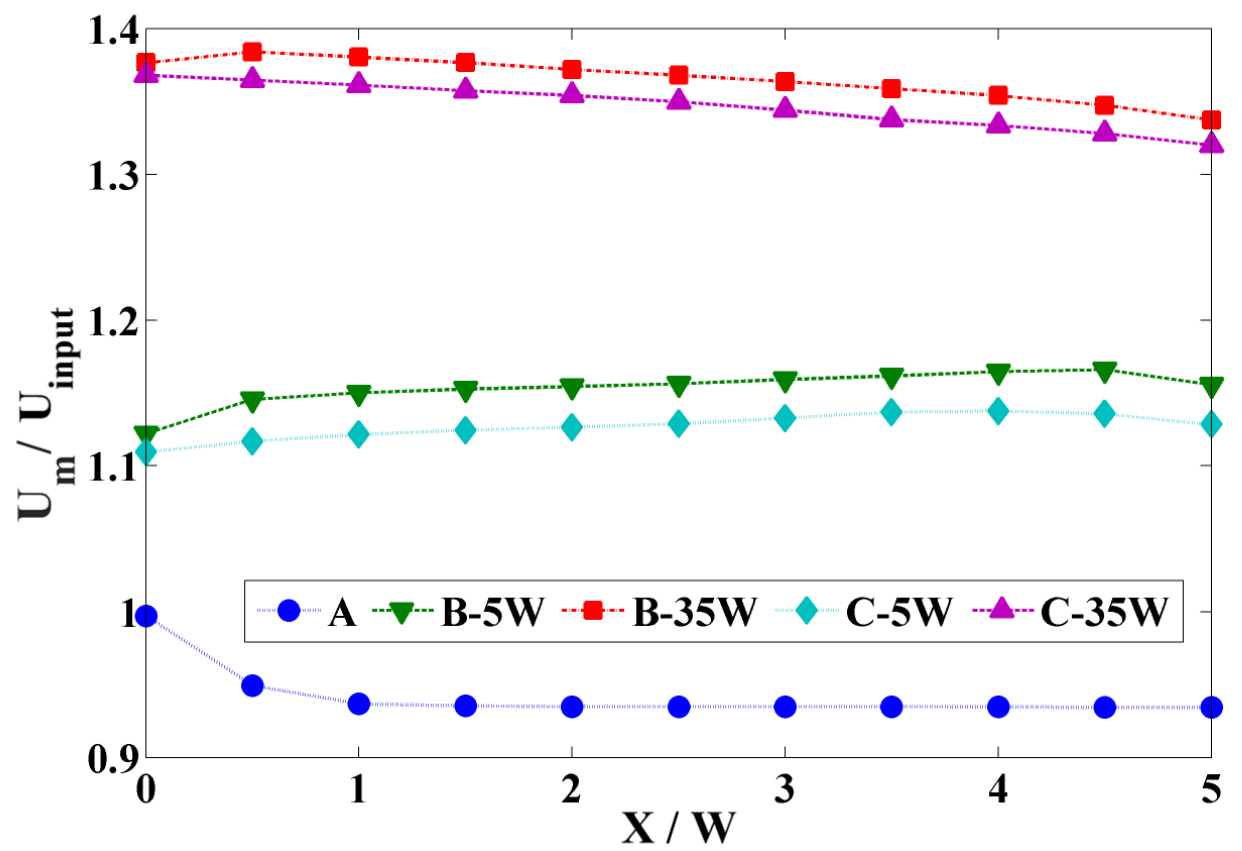

Fig. 6. Impact of the orifice configuration on the evolution of the centerline velocity with distance from orifice. The labels ' $5 W$ ' and ' $35 W$ ' in the legend refer to the length of the duct. 
Fig. 6 reveals the impact of the configuration on the evolution of the centerline velocity with distance from orifice. The following observations are made. First of all, a drop in centerline velocity is observed in configuration A only. This is due to the initial lateral expansion of the flow at the inlet. As mentioned, FDS calculates cell velocities at the center of the cells (staggered grid). For configuration A, the orifice is flush with the floor and the inlet velocity boundary condition is imposed in that plane where the axial $(X)$ velocity is specified. The lateral ( $Y$ and $Z$ ) velocity components are not defined. As a result, the flow can expand in the first cell downstream of the vent, reducing the axial velocity. This can be prevented by adding a duct ahead of the inlet boundary, as the duct keeps the outlet flow in the axial direction, ensuring that the one dimensional axial velocity is preserved at the orifice. In this respect it is also relevant to monitor the magnitude of the wall normal velocity components, which are in principle supposed to be zero (impermeability boundary condition). In other words, the wall normal velocity magnitude is to be considered an error. Yet, FDS uses a direct-forcing Immersed Boundary Method (IBM), as a consequence of which the normal velocity component on an interior obstacle cannot be reduced to zero at machine precision, because a Dirichlet value for pressure is described on that surface that only approximates the Neumann condition that would lead to zero penetration velocity. The maximum allowed normal velocity component on the solid boundary is determined by specifying the 'VELOCITY_TOLERANCE' on the 'PRES' command line. We applied the default value, defined as $\delta x / 2$, with $\delta x$ the characteristic grid cell size. In our case, this yields $\delta x / 2=0.001 \mathrm{~m} / \mathrm{s}$, which is so much smaller than the main flow velocity $(5 \mathrm{~m} / \mathrm{s})$ that the impact on the flow field is negligible.

Secondly, with configuration B, a sudden increase is observed near the orifice. For the case where the duct length is only $5 \mathrm{~W}$, this increase is due to the combined effect of the accelerating flow inside the duct and a (small) vena contracta effect as the flow emerges from the duct. Indeed, the increase in velocity is less pronounced when the duct length equals $35 \mathrm{~W}$ (and the 
flow is no longer accelerating inside the duct).

Finally, in configuration $\mathrm{C}$, there is no vena contracta effect, as the co-flow is well aligned with the flow emerging from the nozzle. Consequently, no increase in velocity is observed if the duct length is sufficiently long for the flow to be fully developed inside the duct (see curve ' $\mathrm{C}$ $-35 \mathrm{~W}$ '). The observed increase for curve ' $\mathrm{C}-5 \mathrm{~W}$ ' is due to the fact that the flow is still accelerating inside the duct. Note also that in configuration $\mathrm{C}$, where the wall is far away from the nozzle, the possible error in wall-normal velocity component at the wall has no impact on the flow emerging from the nozzle.

\subsection{Duct flow}

So far, the discussion has been restricted to square orifices $(2 \mathrm{~cm} \times 2 \mathrm{~cm})$. In practice, the air curtain slot is rectangular. Therefore, a rectangular orifice $(2 \mathrm{~cm} \times 40 \mathrm{~cm})$ is also studied. Stated in another manner, aspect ratio $(\mathrm{AR}=L / W, L>W)$ values of 1 (square duct) and 20 are considered. Table 2 provides an overview with details for the simulated duct flow.

As mentioned, a total calculation time of 5 seconds is set for all simulations and the mean data are calculated over the period of the final 2 seconds, as (quasi-)steady state conditions are reached after 2 seconds. In order to illustrate this, Fig. 7 presents the temporal evolution of stream-wise velocity $U$ (left) and turbulent kinetic energy (right) at axial distance of $X / D_{h}=$ 30 on the centerline, obtained with the 'DEVC' command as mentioned before. The turbulent kinetic energy (TKE) is calculated as $T K E=\frac{1}{2}\left(\overline{u^{\prime 2}}+\overline{{v^{\prime}}^{2}}+\overline{{w^{\prime}}^{2}}\right)$, using turbulence normal stresses $\left(\overline{u^{\prime 2}}, \overline{v^{\prime 2}}\right.$ and $\left.\overline{w^{\prime 2}}\right)$ as obtained with the 'Covariance' option in FDS through the command 'STATISTICS='COV'’[26].

Viscous boundary layers grow downstream, slowing down the axial flow at the wall and 
thereby accelerating the center-core flow. The thickness of the viscous boundary layer increases in the flow direction until the boundary layer reaches the center and thus fills the entire duct. The distance from the duct inlet to the point where the boundary layers merge is called the hydrodynamic entrance length $L_{e}$ [28]. In turbulent flows, the entrance length can be estimated by $L_{e} / D_{h} \approx 1.359 R e^{1 / 4}[29]$ or $L_{e} / D_{h} \approx 4.4 R e^{1 / 6}$ [30]. In the present study, the resulting entrance lengths are reported in Table 2. The Reynolds number is calculated based on the imposed velocity at the inlet and the hydraulic diameter $D_{h}=4 L W / 2(L+W)$.

Table 2. Overview of simulated and analytical entrance lengths.

\begin{tabular}{|c|c|c|c|c|c|c|c|}
\hline \multirow[b]{2}{*}{ Case } & \multirow{2}{*}{$\begin{array}{c}\text { Orifice } \\
\text { dimension } \\
\text { (cm) }\end{array}$} & \multirow{2}{*}{$\begin{array}{l}\text { Duct } \\
\text { length } \\
L / D_{h}\end{array}$} & \multirow{2}{*}{$\begin{array}{c}\text { Inlet } \\
\text { velocity } \\
U(\mathrm{~m} / \mathrm{s})\end{array}$} & \multirow{2}{*}{$\begin{array}{l}\text { Reynolds } \\
\text { number }^{(*)}\end{array}$} & \multicolumn{3}{|c|}{ Entrance length $\left(L_{e} / D_{h}\right)$} \\
\hline & & & & & $\begin{array}{c}1.359 R e^{1 / 4} \\
{[28,29]}\end{array}$ & $\begin{array}{r}4.4 R e^{1 / 6} \\
{[30,31]}\end{array}$ & $\begin{array}{l}\text { CFD } \\
\text { Result }\end{array}$ \\
\hline S-5 & $2 \times 2$ & 40 & 5 & 6732 & 12.31 & 19.11 & $15-20$ \\
\hline S-10 & $2 \times 2$ & 40 & 10 & 13464 & 14.64 & 21.46 & $15-20$ \\
\hline R-5 & $2 \times 40$ & 40 & 5 & 13464 & 14.64 & 21.46 & $7.5-10$ \\
\hline $\mathrm{R}-10$ & $2 \times 40$ & 40 & 10 & 26927 & 17.41 & 24.09 & $7.5-10$ \\
\hline
\end{tabular}

${ }^{(*)}$ Reynolds number is calculated as $R e=\rho U D_{h} / \mu$, taking $\rho=1.205 \mathrm{~kg} / \mathrm{m}^{3}$ and $\mu=$ $1.79 \times 10^{-5} \mathrm{~kg} /(\mathrm{m} \cdot \mathrm{s})$, Square duct: $D_{h}=2 \mathrm{~cm}$, Rectangular duct: $D_{h} \approx 4 \mathrm{~cm}$

In the fully developed flow region, the pressure drops linearly with distance from the orifice, and thus a constant value for pressure gradient $d P / d X$ is observed in this region [30]. Fig. 8 shows the evolution of $d P / d X$ along the centerline and the entrance length can be determined as the location where the value becomes constant. The observed entrance lengths for the square duct flow are well within the range calculated from the analytical correlations as mentioned $[29,30]$. 

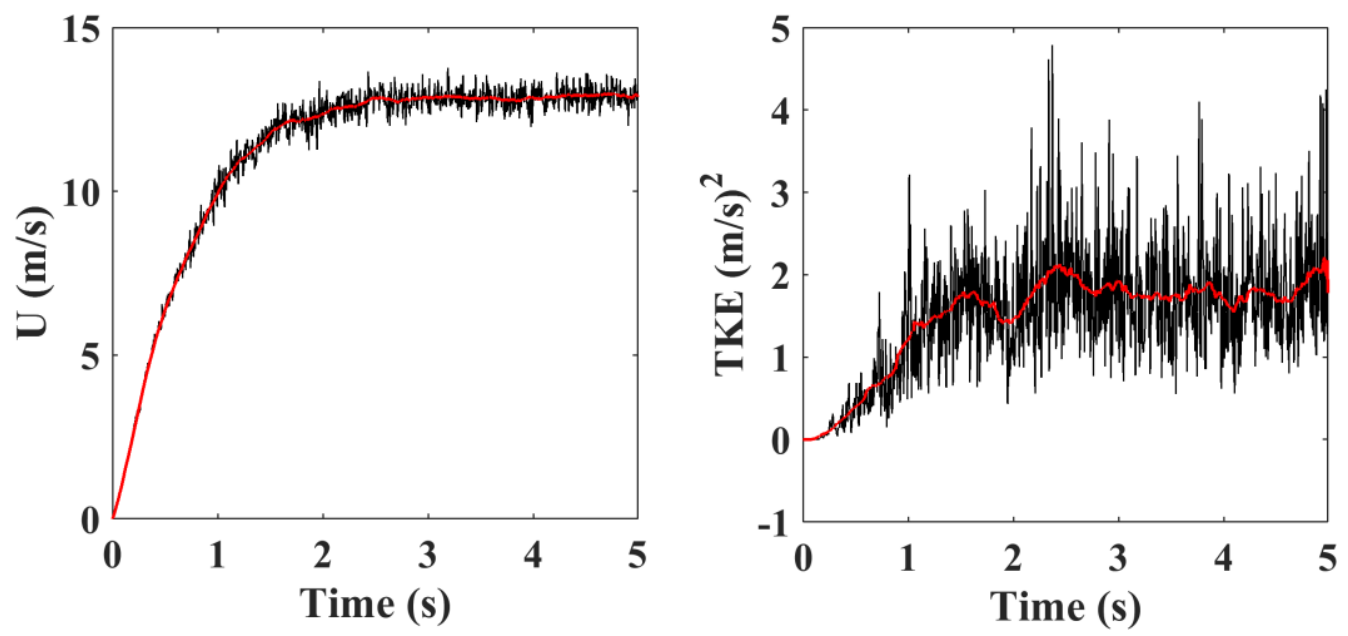

Fig. 7 Temporal evolution of streamwise velocity U (left) and turbulent kinetic energy (right) at axial distance of $X / D_{h}=30$ on the centerline of the duct (case $S$-10). Smooth red lines are obtained by applying the data with moving average filter with span of 5.

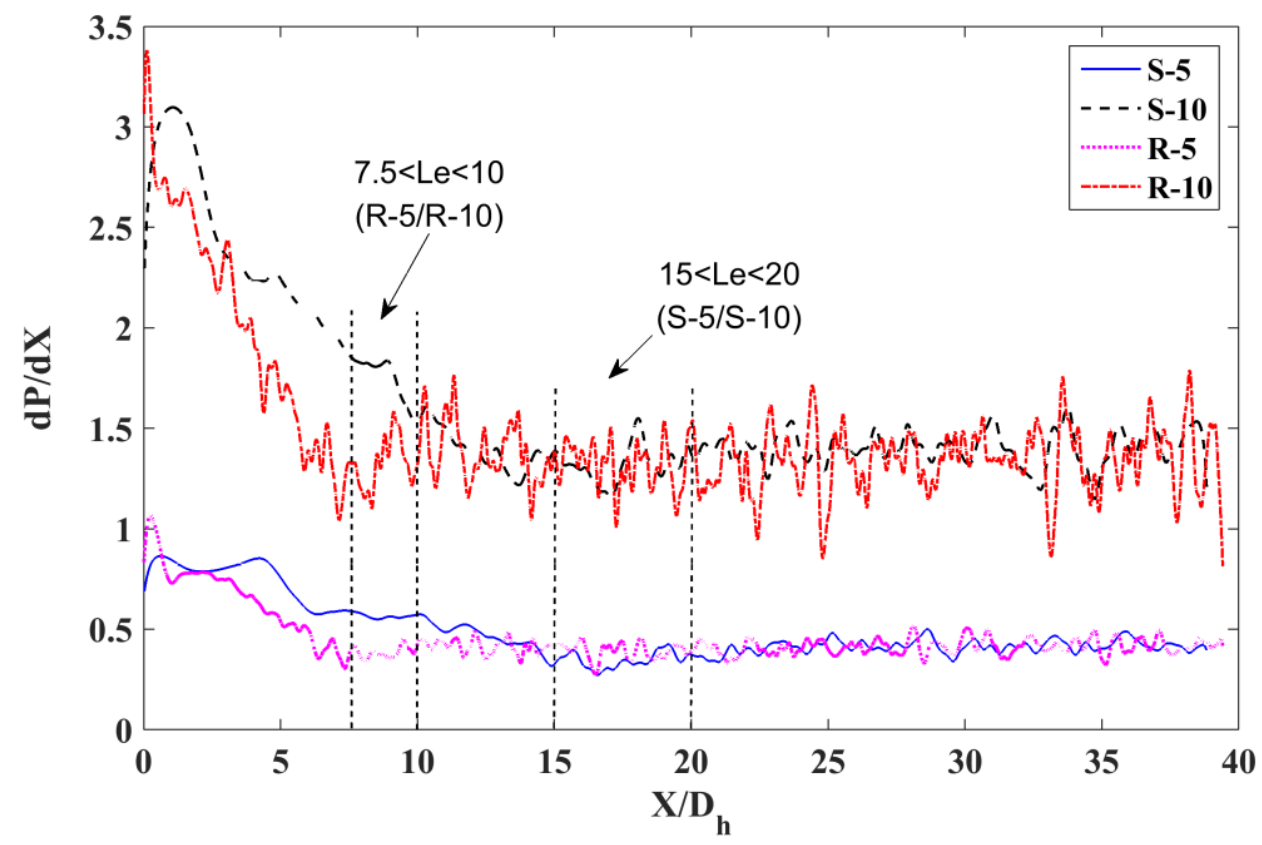

Fig. 8 Evolution of pressure gradient $d P / d X$ along the centerline of a duct flow.

However, the entrance length is under-predicted by a factor of 2 for the rectangular duct (7.5$\left.10 D_{h}\right)$. This suggests that the duct width $W$ should be used as the characteristic length scale for the calculation of entrance length for rectangular ducts with large aspect ratio in the analytical 
equations $[29,30]$, which were deduced originally for circular pipe flows.

Another way of studying the entrance length is based on the axial development of the normalized mean stream-wise velocity $U_{m} / U_{0, c}$ as shown in Fig.9. Beyond the entrance length $X=L_{e}$ the velocity profile does not vary with $X$. Fig. 9 confirms the observations from Fig. 8. The ratio of centerline velocity to the centerline velocity at the inlet decreases with increasing Reynolds number, as expected: as the flow becomes more turbulent, the profiles of stream-wise velocity become flatter and the gradients in the wall region become steeper due to increased turbulent mixing (see also Fig. 10). On the other hand, the velocity ratio $U_{m} / U_{0, c}$ for rectangular duct is lower than that of square duct for the same Reynolds number, because there is no lateral boundary layer development, as illustrated in Fig. 10. The accuracy of the profiles is discussed below (Fig. 13).

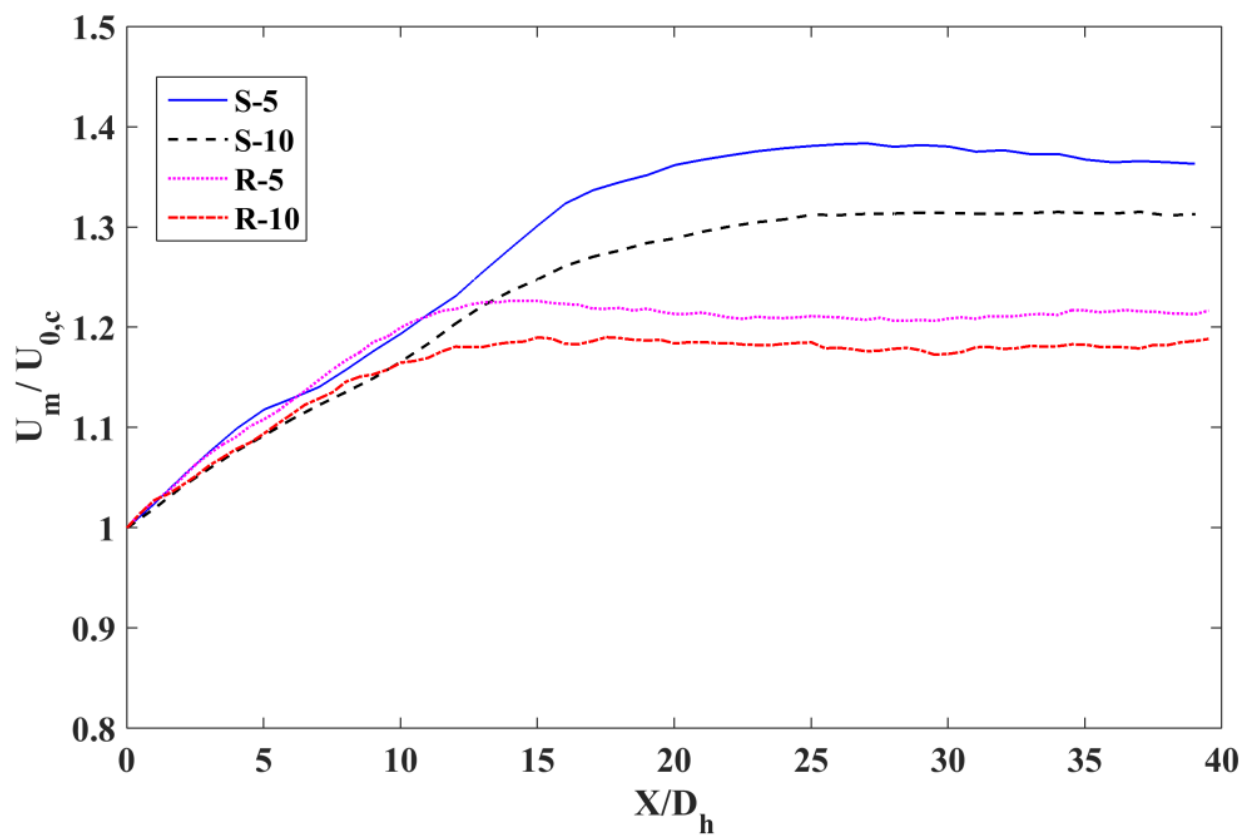

Fig. 9 Evolution of the normalized stream-wise velocity $\left(U_{m} / U_{0, c}\right)$ along the centerline of a duct flow. 


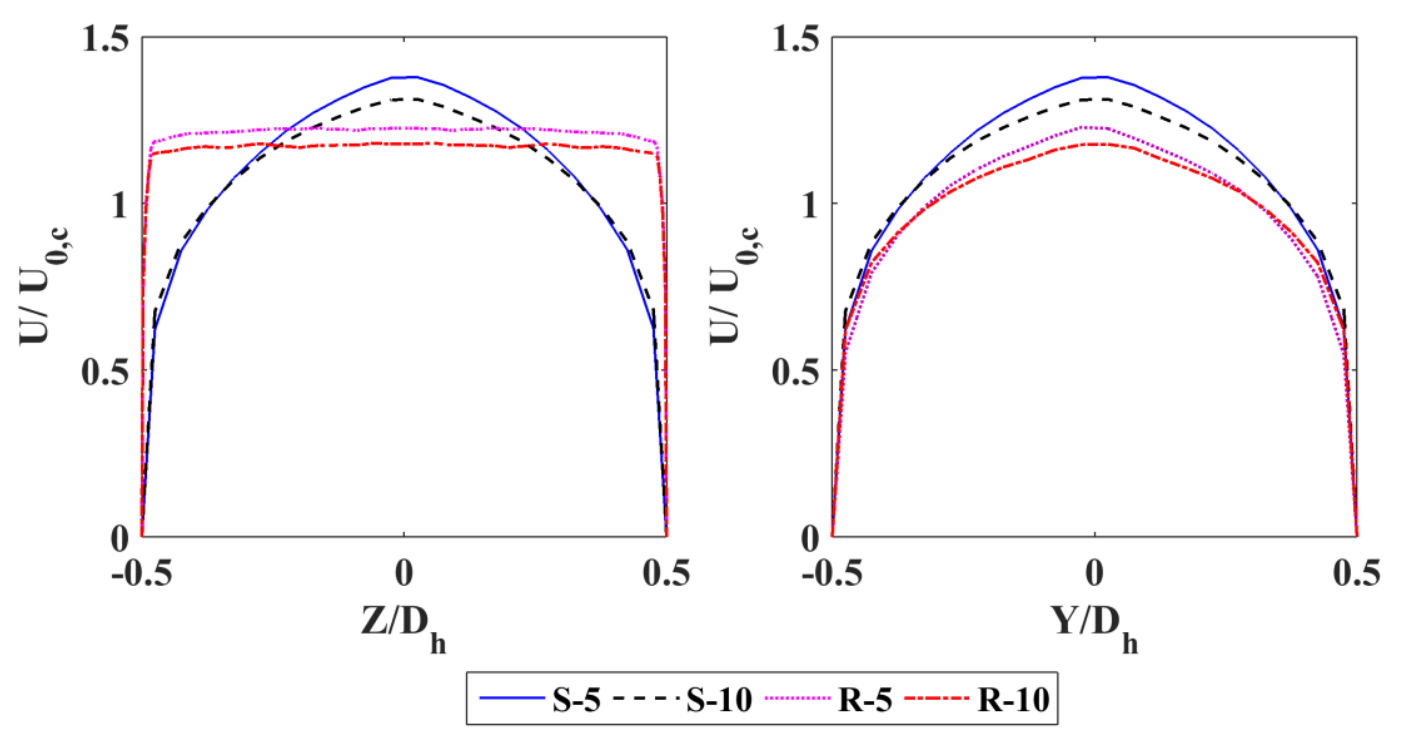

Fig. 10 Normalized mean streamwise velocity profiles in the symmetry plane across the long side (left) and short side (right) of the duct at $X / D_{h}=30$.

Fig. 11 shows the evolution of mean turbulence kinetic energy (TKE) along the centerline. It is again in line with the observations for the entrance length made from Fig. 8 and 9: the TKE profiles reach a plateau at about 15 to $20 D_{h}$ for the square duct and about 7.5 to $10 D_{h}$ for the rectangular duct flow, respectively. The turbulent kinetic energy increases with the Reynolds number. The absolute values are lower in the rectangular duct, in line with the lower values for mean velocity (Fig. 10). 


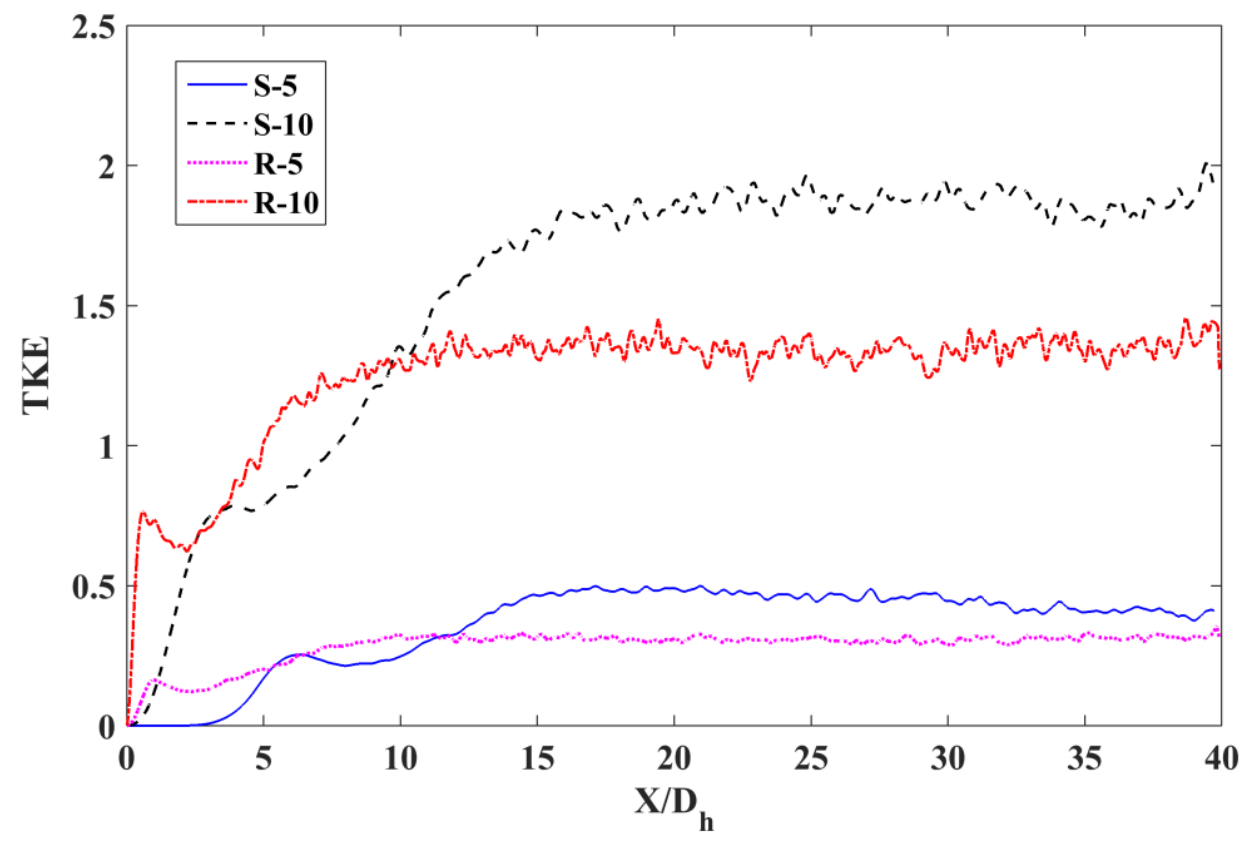

Fig. 11 Evolution of mean turbulence kinetic energy (TKE) along the centerline of a duct flow.

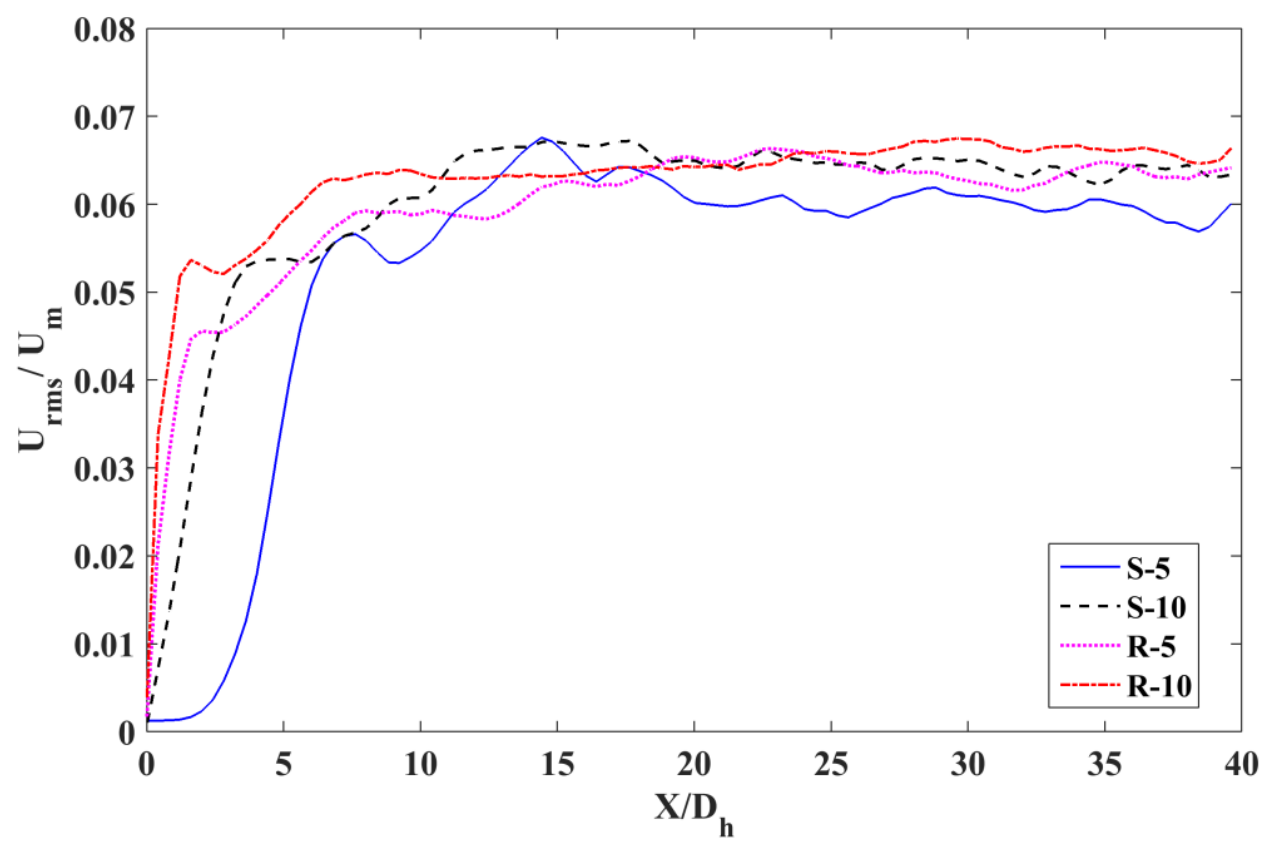

Fig. 12 Evolution of the turbulence intensity $\left(I=U_{R M S} / U_{m}\right)$ along the centerline of a duct flow.

Fig. 12 indeed confirms that differences in turbulence intensity $\left(I=U_{r m s} / U_{m}\right)$ are much 
smaller (albeit that the intensity also still increases with the Reynolds number, as expected). $U_{r m s}$ is the root mean square of turbulent velocity fluctuation obtained from statistical outputs by setting STATISTICS = 'RMS' on the DEVC line. The accuracy is discussed below (Fig. 14).

Fig. 13 presents the profiles of Fig. 10 in the form $U / U_{m}$ in order to compare the simulation results to experimental data [32], DNS data [33] and other LES results [34]. Except perhaps for the S-5 case, with the lowest Reynolds number, all profiles are well within the range of data. Similar results reflecting the influence of Reynolds number were also found in [35].

Similarly, the turbulence intensities are presented in Fig. 14. For the LES of [34], no results are available for $\mathrm{Re}=25000$, so only results for $\mathrm{Re}=4410$ are plotted. Fig. 14 confirms the accuracy of the results obtained.

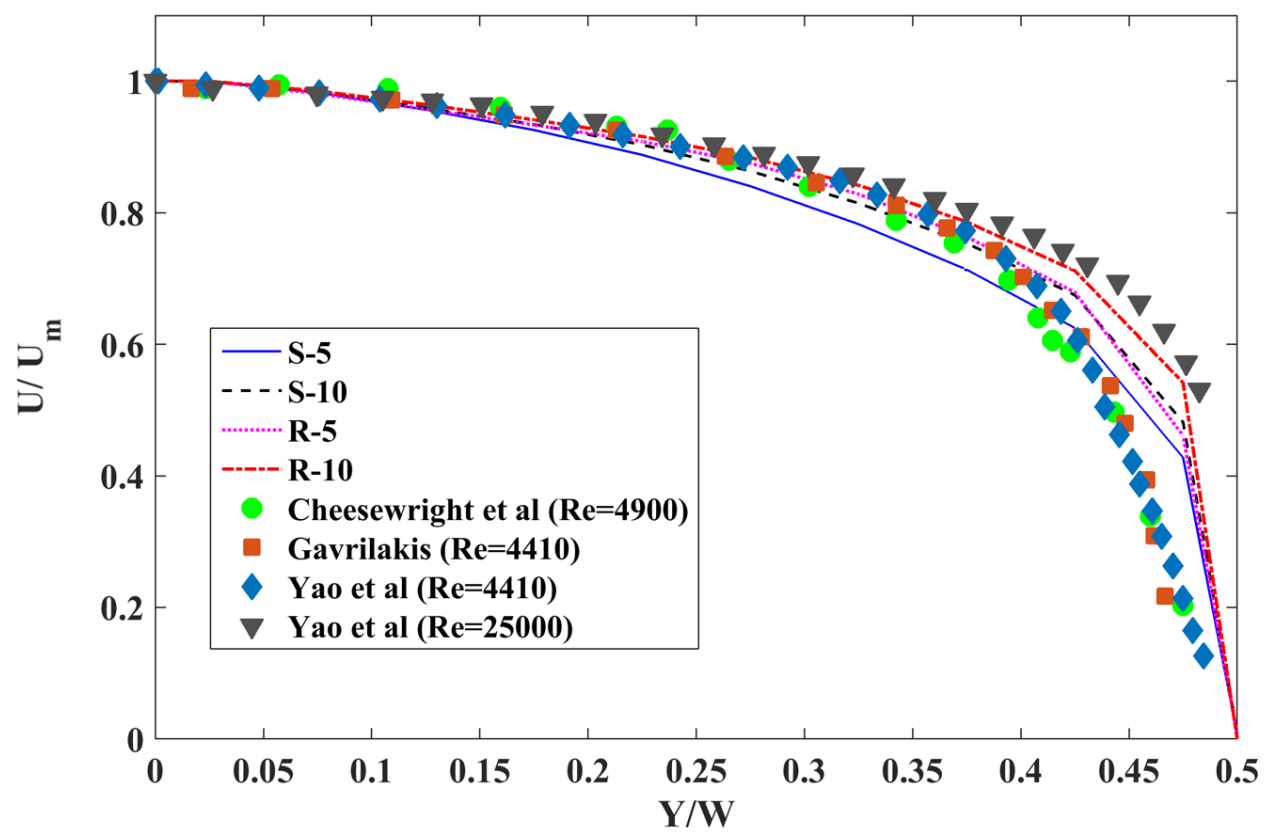

Fig. 13 Comparison of the normalized mean streamwise velocity (at $X / D_{h}=30$ ) to experimental data of Cheesewright et al [32], DNS data of Gavrilakis[33] and LES data of Yao [34]. 


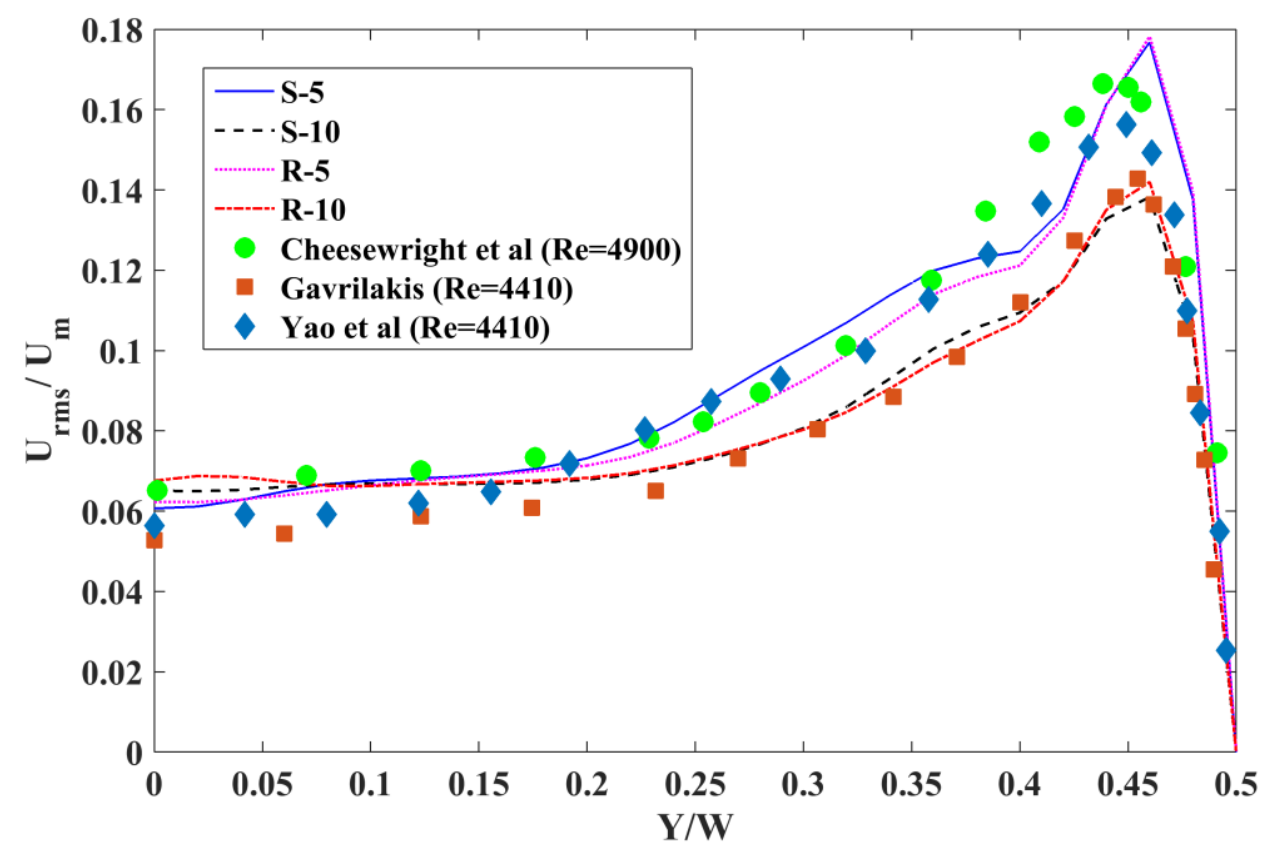

Fig. 14 Comparison of the turbulence intensities (at $\left.X / D_{h}=30\right)$ to the experimental data of Cheesewright et al [32], DNS data of Gavrilakis[33] and LES data of Yao [34].

\section{Conclusions}

An analysis has been conducted on the impact of the velocity inlet boundary condition, in combination with the mesh size, on the flow field in the near-field region of an air curtain flow, using FDS, Version 6.0.1.

With respect to the mesh size, the overall conclusion is that the use of a sufficiently fine mesh, i.e., 10 cells across the characteristic dimension of the nozzle, the evolution of the mean and RMS stream-wise velocity along the centerline, as well as their profiles across the nozzle width, are captured accurately in the CFD results. The accuracy has been illustrated by comparison of the CFD results to experimental data, DNS data and other LES results.

Although correct mass and momentum flow rates are injected in the FDS simulations through a staggered approach, it has been illustrated that interpolation in post-processing/visualization 
in Smokeview can result in misleading observations in the output. Differences become smaller as the mesh is finer. Using the commands 'DUMP' for a data matrix and 'DEVC' for single data at specific location provides raw data directly, avoiding this issue. In more recent FDS versions, this can also be done for wall quantities and vectors.

Providing a duct ahead of the orifice exit in the simulations, a small vena contracta effect is observed when the orifice is flush with a solid boundary. This vena contracta effect correctly disappears if the duct is moved inside the domain, because the co-flow is then aligned with the jet flow at the orifice exit.

A duct length of at least $20 \mathrm{~W}$ is required for the flow to become fully developed inside the duct, starting from a top hat velocity profile at the inlet. The simulation results confirm analytical correlations for the ratio of the entrance length to the hydraulic diameter of the duct for square ducts. However, for rectangular ducts, the correlations only agree with the CFD results if the duct width, rather than the hydraulic diameter, is used as the characteristic length scale.

\section{Acknowledgements}

This research has been conducted at Ghent University, supported by the National Natural Science Foundation of China (Grant No. 51608076), Chongqing Science and Technology Commission (Grant No. cstc2016shmszx30016), Chongqing Construction Science and Technology Planning Project (Grant No. 2015-1-34), Fundamental Research Funds for the Central Universities (Grant No. 106112015CDJXY210008), State Scholarship Fund (Grant No. 201306050081) and the 111 Project, No. B13041. The authors greatly acknowledge Dr. Randall McDermott (NIST, USA) for the inspiring communication concerning the implementation details in FDS, version 6.0.1. Dr. Tarek Beji is Postdoctoral Fellow of the Fund of Scientific Research - Flanders (Belgium) (FWO-Vlaanderen). The computational resources (Stevin 
Supercomputer Infrastructure) and services used in this work were provided by the VSC

(Flemish Supercomputer Center), funded by Ghent University, the Hercules Foundation and the Flemish Government - department EWI. 


\section{References}

1. Ji J, Wan H, Li K, Han J, Sun J (2015) A numerical study on upstream maximum temperature in inclined urban road tunnel fires. International Journal of Heat and Mass Transfer 88:516526. doi:https://doi.org/10.1016/j.ijheatmasstransfer.2015.05.002

2. Vauquelin O (2008) Experimental simulations of fire-induced smoke control in tunnels using an "air-helium reduced scale model": Principle, limitations, results and future. Tunnelling and Underground Space Technology 23 (2):171-178. doi:https://doi.org/10.1016/j.tust.2007.04.003 3. Moriyama S (2011) Smoke Control System for High-Rise Buildings in Japan. Journal of Disaster Research 6 (6):551-552. doi:https://doi.org/10.20965/jdr.2011.p0551

4. Ciocănea A, Dragomirescu A (2013) Modular ventilation with twin air curtains for reducing dispersed pollution. Tunnelling and Underground Space Technology 37 (0):180-198. doi:https://doi.org/10.1016/j.tust.2013.03.012

5. Shih Y-C, Yang A-S, Lu C-W (2011) Using air curtain to control pollutant spreading for emergency management in a cleanroom. Building and Environment 46 (5):1104-1114. doi:https://doi.org/10.1016/j.buildenv.2010.11.011

6. Foster AM, Barrett R, James SJ, Swain MJ (2002) Measurement and prediction of air movement through doorways in refrigerated rooms. International Journal of Refrigeration 25 (8):1102-1109. doi:https://doi.org/10.1016/S0140-7007(01)00108-6

7. Hu S-C, Lin T, Fu B-R, Wang T-Y (2017) Air curtain application in a purged unified pod. $\begin{array}{lll}\text { Applied } & \text { Thermal 111:1179-1183. }\end{array}$ doi:https://doi.org/10.1016/j.applthermaleng.2016.10.022

8. Standard PsRoCMI (1999) Air curtain. vol JB/T 9067-1999. China Standard Press, Beijing 
9. Sakurai H, Hayashi T, Shibata M, Kanehara K (1980) Researches on air shutter for fire defence. Fire Safety Journal 2 (1):9-16. doi:https://doi.org/10.1016/0379-7112(79)90011-0 10. Guyonnaud L, Solliec C, de Virel MD, Rey C (2000) Design of air curtains used for area confinement in tunnels. Experiments in Fluids 28 (4):377-384. doi:https://doi.org/10.1007/s003480050397

11. Elicer-Cortés JC, Demarco R, Valencia A, Pavageau M (2009) Heat confinement in tunnels between two double-stream twin-jet air curtains. International Communications in Heat and Mass Transfer 36 (5):438-444. doi:https://doi.org/10.1016/j.icheatmasstransfer.2009.01.019

12. Felis F, Pavageau M, Elicer-Cortés JC, Dassonville T (2010) Simultaneous measurements of temperature and velocity fluctuations in a double stream-twin jet air curtain for heat confinement in case of tunnel fire. International Communications in Heat and Mass Transfer 37 (9):1191-1196. doi:https://doi.org/10.1016/j.icheatmasstransfer.2010.07.018

13. Hu LH, Fong NK, Yang LZ, Chow WK, Li YZ, Huo R (2007) Modeling fire-induced smoke spread and carbon monoxide transportation in a long channel: Fire Dynamics Simulator comparisons with measured data. Journal of Hazardous Materials 140 (1-2):293-298. doi:https://doi.org/10.1016/j.jhazmat.2006.08.075

14. Hu LH, Zhou JW, Huo R, Peng W, Wang HB (2008) Confinement of fire-induced smoke and carbon monoxide transportation by air curtain in channels. Journal of Hazardous Materials 156 (1-3):327-334. doi:https://doi.org/10.1016/j.jhazmat.2007.12.041

15. Luo N, Li A, Gao R, Zhang W, Tian Z (2013) An experiment and simulation of smoke confinement utilizing an air curtain. Safety Science 59 (0):10-18. doi:https://doi.org/10.1016/j.ssci.2013.04.009 
16. Yu L-X, Liu F, Merci B (2015) Analysis of the impact of the inlet boundary conditions in FDS results for air curtain flows in the near-field region. Paper presented at the Ninth Mediterranean Combustion Symposium, Rhodes, Greece,

17. Yu L-X, Beji T, Zadeh SE, Liu F, Merci B (2016) Simulations of Smoke Flow Fields in a Wind Tunnel Under the Effect of an Air Curtain for Smoke Confinement. Fire Technology 52 (6):2007-2026. doi:https://doi.org/10.1007/s10694-016-0598-y

18. McGrattan K, McDermott R, Floyd J, Hostikka S, Forney G, Baum H (2012) Computational fluid dynamics modelling of fire. International Journal of Computational Fluid Dynamics 26 (6-8):349-361. doi:http://dx.doi.org/10.1080/10618562.2012.659663

19. Jarrin N, Prosser R, Uribe J-C, Benhamadouche S, Laurence D (2009) Reconstruction of turbulent fluctuations for hybrid RANS/LES simulations using a synthetic-eddy method. International Journal of Heat and Fluid Flow 30 (3):435-442. doi:https://doi.org/10.1016/j.ijheatfluidflow.2009.02.016

20. Bradbury L (1965) The structure of a self-preserving turbulent plane jet. Journal of Fluid Mechanics 23 (01):31-64. doi:https://doi.org/10.1017/S0022112065001222

21. Heskestad G (1965) Hot-wire measurements in a plane turbulent jet. Journal of Applied Mechanics 32 (4):721-734. doi:https://doi.org/10.1115/1.3625158

22. Gutmark E, Wygnanski I (1976) The planar turbulent jet. Journal of Fluid Mechanics 73 (03):465-495. doi:https://doi.org/10.1017/S0022112076001468

23. Shestakov MV, Dulin VM, Tokarev MP, Sikovsky DP, Markovich DM (2015) PIV study of large-scale flow organisation in slot jets. International Journal of Heat and Fluid Flow 51:335352. doi:https://doi.org/10.1016/j.ijheatfluidflow.2014.10.027 
24. Browne L, Antonia R, Chambers A (1984) The interaction region of a turbulent plane jet. Journal of fluid mechanics 149:355-373. doi:https://doi.org/10.1017/S002211208400269X

25. McGrattan K, Hostikka S, McDermott R, Floyd J, Weinschenk C, Overholt K (2013) Fire Dynamics Simulator, Technical Reference Guide, Volume 1: Mathematical Model. NIST Special Publication 1018, Sixth edn. National Institute of Standards and Technology, Gaithersburg, Maryland, USA, and VTT Technical Research Centre of Finland, Espoo, Finland. doi:10.6028/NIST.SP.1018-1

26. McGrattan K, Hostikka S, McDermott R, Floyd J, Weinschenk C, Overholt K (2013) Fire Dynamics Simulator, User's Guide. NIST Special Publication 1019, Sixth edn. National Institute of Standards and Technology, Gaithersburg, Maryland, USA, and VTT Technical Research Centre of Finland, Espoo, Finland. doi:10.6028/NIST.SP.1019

27. Beale SB (2005) Mass transfer in plane and square ducts. International Journal of Heat and Mass Transfer 48 (15):3256-3260.

doi:https://doi.org/10.1016/j.ijheatmasstransfer.2005.02.037

28. Yunus AC, Cimbala JM (2006) Fluid mechanics: fundamentals and applications. International Edition, McGraw Hill Publication:185-201

29. Wang Z (1982) Study on correction coefficients of laminar and turbulent entrance region effect in round pipe. Applied Mathematics \& Mechanics 3 (3):433-446. doi:https://doi.org/10.1007/BF01897224

30. Munson BR, Young DF, Okiishi TH (1990) Fundamentals of fluid mechanics. Wiley, New York

31. White FM (1999) Fluid mechanics, WCB. ed: McGraw-Hill, Boston. 
32. Cheesewright R, McGrath G, Petty D (1990) LDA measurements of turbulent flow in a duct of square cross section at low Reynolds number. Aeronautical Engineering Dept Rep ER 1011

33. Gavrilakis S (1992) Numerical-Simulation of Low-Reynolds-Number Turbulent-Flow Through a Straight Square Duct. Journal of Fluid Mechanics 244:101-129. doi:https://doi.org/10.1017/s0022112092002982

34. Yao J, Zhao Y, Fairweather M (2015) Numerical simulation of turbulent flow through a straight square duct. Applied Thermal Engineering 91:800-811. doi:https://doi.org/10.1016/j.applthermaleng.2015.08.065

35. Zhang H, Trias FX, Gorobets A, Tan Y, Oliva A (2015) Direct numerical simulation of a fully developed turbulent square duct flow up to Re-tau=1200. International Journal of Heat and Fluid Flow 54:258-267. doi:https://doi.org/10.1016/j.ijheatfluidflow.2015.06.003 